\title{
Retórica, Dialética e Lógica: a inútil busca por uma distinção essencial ${ }^{\star}$
}

\section{Charlotte Jørgensen}

Docente da Universidade de Copenhagen, Dinamarca

Tradução:

Ana Lúcia Magalhães

Pontifícia Universidade Católica de São Paulo

Resumo: Tomando como ponto de partida a recente contribuição de Blair ao debate sobre a tríade, o artigo discute e desafia tentativas de reduzir a intrincada relação entre retórica, dialética e lógica a uma tricotomia com compartimentos estanques ou separá-los com um único critério totalmente nítido. Argumento que os esforços para apontar uma diferença essencial, entre as várias diferenças típicas parcialmente fundamentadas em tradições disciplinares, obscurecem as complexidades existentes em cada campo. negligenciadas tanto as propriedades transversais dos campos como as possibilidades de pontes teóricas entre eles.

Palavras-chave: Teoria da Argumentação. Dialética. Lógica. Retórica.

Abstract: Taking Blair's recent contribution to the debate about the triad as its starting point, the article discusses and challenges attempts to reduce the intricate relationship between rhetoric, dialectic and logic to a trichotomy with watertight compartments or to separate them with a single clear-cut criterion. I argue that efforts to pinpoint an essential difference, among the various typical differences partly grounded in disciplinary traditions, obscure the complexities within the fields. As a consequence, crosscutting properties of the fields as well as the possibilities for theoretical bridging between them are neglected.

Keywords: Argumentation Theory. Dialectic. Logic. Rhetoric.

\footnotetext{
" A Revista EID\&A agradece vivamente o Professor Cristopher Tindale, diretor da Revista Informal Logic, e a Professora Charlotte Jørgensen, autora, por autorizarem a publicação da tradução do artigo encontrado originalmente em Informal Logic, v. 34, n. 2, 2014.
} 


\section{Introdução}

Este artigo dá continuidade ao debate sobre a relação entre os três campos tradicionais da teoria da argumentação (retórica, dialética e lógica), tomando como ponto de partida a recente contribuição de Blair (2012) sobre o tema'. Blair desafia a conhecida visão de Wenzel (1990) de que a diferença reside em três perspectivas, relativas a processo, procedimento e produto. Além disso, questiona a visão alternativa proposta especialmente por Kock (2009) de que a característica que dá a distinção é o domínio tópico do campo. Blair então apresenta sua alternativa: a retórica estuda os argumentos em discursos, a dialética em conversações e a lógica estuda o bom raciocínio em ambas.

Compartilho muitos de seus pontos e objeções aos pontos de vista de outras pessoas sobre o assunto, mas discordo da divisão proposta por Blair. Quando argumento contra essa divisão - e também contra a de Kock - no texto que segue, meu principal objetivo é desafiar qualquer esforço para reduzir a relação intrincada entre os campos da tríade a uma tricotomia estanque ou a um único critério. Embora eu endosse a lista tradicional de diferenças e semelhanças típicas para caracterizar sua relação mútua, considero uma busca inútil a tentativa de enfatizar uma delas como a característica diferenciadora significativa. Como Johnson (2009), penso que esforços desse tipo obscurecem as complexidades dentro dos campos da tríade, e também que muitas das diferenças entre eles se devem às nossas respectivas tradições disciplinares. Além disso, sugiro que, na busca da diferença essencial entre os campos, corremos o risco de contornar o entrelaçamento e a sobreposição de retórica, dialética e lógica, e assim as possibilidades de pontes teóricas entre eles.

Nas seções dois e três adiante, discuto as distinções propostas por Blair e Kock. $\mathrm{Na}$ quarta seção, discuto algumas implicações da redução das diferenças entre os três campos e sugiro uma alternativa de abordagem da relação entre eles. Antes de prosseguir, entretanto, são apropriadas algumas observações terminológicas preliminares e demarcações.

A primeira observação diz respeito aos termos que usamos para designar retórica, dialética e lógica e a relação entre elas. São 'disciplinas', 'artes', 'ciências', 'tradições de pesquisa', 'perspectivas' ou outras designações? Johnson (2009, p. 5, 18), por exemplo, insiste que a dialética hoje em dia não é uma disciplina, presumivelmente

10 presente artigo é baseado em um trabalho apresentado na $10^{\mathrm{a}}$ conferência OSSA na Universidade de Windsor, 2013, e é uma revisão da publicação nos Anais (JØRGENSEN, 2014). 
porque não é ensinada nos currículos universitários como era no passado. Ele também chama a atenção para a imprecisão do perspectivismo do conceito de Wenzel, referindo-se (na nota 4) a Hans Hansen, que em discussão perguntou: O que é uma perspectiva? Johnson admite a relevância da questão, mas não a elabora, e utiliza expressões como as três "abordagens" (por exemplo, p. 8) e "comunidades (de investigação)" (p. 11-12). Já que eu argumento contra a tendência de compartimentalizar a retórica, a dialética e a lógica, acho que esses termos elásticos se adequam ao meu propósito e os chamo de "campos".

Além disso, uso o termo "tríade" quando me refiro coletivamente a esses campos. Desejo enfatizar que meu foco nos três campos não implica qualquer intenção de excluir abordagens à argumentação provenientes de outros campos de estudo. Em outras palavras, compartilho da preocupação de Johnson de que o modelo padrão tripartido de Wenzel concebido na Visão do Triunvirato corre o risco de apoiar "tendências exclusivistas". O fato de as três tradições clássicas terem dominado a teoria da argumentação em uma ampla perspectiva histórica não significa, é claro, que no contexto moderno não devamos receber contribuições de outros campos, como por exemplo Comunicação, Linguística, Ciência da Computação, Psicologia, Ciência Política ou Direito (cf. Johnson, 2009, p. 7).

\section{A distinção tripartite de Blair}

As primeiras seções do artigo de J. Anthony Blair (2012), "Rhetoric, Dialectic, and Logic as Related to Argument", progridem como uma crítica da distinção de Wenzel (1990) processo-procedimento-produto que se tornou um modelo padrão para caracterizar as perspectivas atinentes à retórica-dialética-lógica, respectivamente. Blair (2012) aponta de forma convincente vários problemas e deficiências deste "modelo de perspectiva" que surgem quando se submete esse modelo a uma inspeção mais detalhada. Além disso, Blair (2012, p. 154-155) considera que, embora Aristóteles seja "sem dúvida a fonte da tricotomia lógica/dialética/retórica", é “um exagero" dizer que Aristóteles apresenta três perspectivas de argumentação nos Analíticos Anteriores, nos Tópicos e na Retórica. A expressão "distender" indica que "perspectivas" também não estão longe do objetivo. Em alguns de seus sentidos, a palavra "perspectiva" parece apropriada para caracterizar a visão aristotélica da relação entre os três campos. Quando, por exemplo, Aristóteles, na frase de abertura de sua Retórica, descreve a 
retórica como "antístrofe"2 da dialética, isso chega próximo, em termos modernos, de dizer que elas representam duas perspectivas da argumentação. Ao usar essa metáfora teatral e métrica, Aristóteles - referindo-se sutilmente a Platão - coloca os dois campos argumentativos em situação de igualdade, ao mesmo tempo espelhando e contrastando um ao outro devido às semelhanças que compartilham e às diferenças com as quais se complementam (cf. Kennedy, 1991, p. 28-29, nota 2). Além disso, podese sustentar que Aristóteles, ao estar “interessado nas leis da dedução, nas estratégias para ganhar disputas de diálogo e métodos para discursos persuasivos, respectivamente" (BLAIR, 2012, p. 155), representa uma visão em perspectiva, no mínimo, no sentido de que os três aspectos são relevantes para a prática argumentativa e nenhum deles sozinho é suficiente como uma teoria de argumentação universal.

Após a cautelosa conclusão em que considera "um anacronismo encontrar em Aristóteles a tese de que lógica, dialética e retórica são três perspectivas de argumentação" (BLAIR, 2012, p. 155), Blair se volta para o que ele considera uma alternativa ao modelo de perspectiva de Wenzel, proposto por Kock (2009) e compartilhado, ao menos em parte, por Tindale (1999) e Hauser (2002): a visão de que a principal diferença entre os campos é o seu domínio tópico. Voltarei a essa alternativa na seção três a seguir.

Ao considerar ambos os modelos inadequados para capturar a relação dentro da tríade, Blair (2012, p. 157-162), em sua seção final, os substitui por seu próprio modelo. Resumidamente, a retórica refere-se a argumentos em discursos, a dialética diz respeito a argumentos em conversações e a lógica relaciona-se ao bom raciocínio tanto em discursos quanto em conversação. Blair (2012) desdobra essa tricotomia em duas etapas. Primeiro, ele discute a relação entre retórica e dialética e a seguir sugere de que forma a lógica está relacionada a ambas. A seguir, portanto, abordo a tricotomia de Blair nesta ordem.

Seguindo a sugestão de Krabbe (2000), Blair modifica o traço distintivo para o "tipo de discurso", ou seja, o formato comunicativo associado aos dois campos, em particular os papéis dos participantes envolvidos na configuração argumentativa: discursos retóricos são instâncias de comunicação unilateral de um retor que argumenta para uma audiência heterogênea; as conversações dialéticas são um

\footnotetext{
2 N.T.: Antístrofe, figura baseada nas diferenças de sentido que resultam da associação das mesmas palavras em um mesmo tipo de construção sintática com inversão de sua ordem, como em filosofia da miséria e miséria da filosofia (Dicionário Oxford - languages.oup.com/google-dictionary-pt/).
} 
discurso argumentativo de troca de turnos entre dois interlocutores que interagem diretamente. Blair demonstra o contraste com a seguinte sugestão:

[...] é a natureza não interativa e diversa do destinatário nos discursos que dá origem ao complexo de propriedades tipicamente associado à Retórica, ao passo que é a natureza interativa e homogênea do interlocutor nas conversas que dá origem ao complexo de propriedades tipicamente associado à dialética. E são essas as diferenças que, por sua vez, afetam as propriedades retóricas e dialéticas dos argumentos nos dois casos (BLAIR, 2012, p. 161).

Minha primeira objeção a essa caracterização do vínculo entre retórica e dialética coincide com a reação fundamental de Johnson à tricotomia padrão de Wenzel, ou seja, a de que não existe a perspectiva retórica, dialética ou lógica 3 . O fato de que Blair está ciente dessa concepção errônea da tríade está claramente afirmado na introdução, em que ele cita que a principal preocupação de Johnson é a de que "não existe, em cada caso, uma perspectiva retórica, dialética ou lógica única”, mas "muitos entendimentos diferentes e, às vezes, incompatíveis em cada caso", e que sugerir o contrário seria uma "simplificação enganosa". Blair, portanto, admite que há muitas retóricas etc. No entanto, ele sustenta que, "apesar das diferenças internas entre as concepções de retórica, dialética e lógica”, é possível sustentar a visão de que existem três perspectivas amplas, uma vez que "os lógicos em disputa podem ser distinguidos dos dialéticos em disputa, e ambos podem ser distinguidos dos retóricos em disputa" (BLAIR, 2012, p. 149-150).

Em parte, Blair está certo, é claro. No entanto, se tornamos uma característica a essencial, não deveríamos então esperar que isso seja realmente algo em que os membros de cada campo, apesar de suas disputas internas, possam concordar - pelo menos em termos gerais? Minha resposta a essa questão é que a maioria dos retóricos irão se opor à sugestão de que a argumentação retórica se limita aos discursos (peças de oratória?) ou que os discursos (peças de oratória?) são mais importantes para a retórica do que outros tipos de discurso. É verdade que nenhum retórico negará que os discursos retóricos monologais ${ }^{4}$ desempenham um papel importante entre os tipos

\footnotetext{
3 Embora Johnson esteja certo em chamar a atenção para o equívoco de que há unanimidade dentro de cada campo, essa objeção representa uma interpretação errada de Wenzel. Parece incompatível com a abordagem pluralista que permeia sua recomendação de adotar uma visão em perspectiva. Wenzel $(1990$, p. 21) certamente reconhece a diversidade dentro dos campos, referindo-se, por exemplo, "às muitas outras abordagens da teoria retórica nos tempos modernos". Nesse sentido, Gilbert $(2014$, p. 2) aponta que Wenzel usou a expressão "principais perspectivas" para indicar que elas não são as únicas.

${ }^{4}$ N.T.: Para marcar a distinção que a autora faz entre discurso monologal como objeto da retórica e discurso dialogal como objeto da dialética, optamos por traduzir "speeches" por "discursos retóricos monologais".
} 
de discurso estudados pela retórica, mas nenhum retórico dentro da academia afirmaria que tais discursos são, por princípio, mais essenciais para a retórica do que, por exemplo, o discurso escrito. Identificar retórica com os discursos retóricos monologais pode ser mais verdadeiro em relação à retórica clássica do que à retórica moderna e ninguém pode negar que a teoria da retórica surgiu em conexão com a oratória. No entanto, muitos argumentariam que isso ocorria porque a comunicação pela fala era o meio predominante para o discurso público na antiguidade, mas isso não significa que o discurso retórico deva ser oral. A análise de Frentz do filme My Dinner with Andre "como um exemplo paradigmático de uma conversa retórica" (FRENTZ, 1999 [1985], p. 295) pode servir como uma ilustração de crítica retórica que abrange muito mais do que o discurso oral e escrito sustentado associado à retórica dominante.

Estou ciente de que talvez esteja tratando a distinção de Blair de modo demasiadamente literal. Em conexão com a observação de que o auditório dos discursos retóricos monologais não responde da mesma forma que os parceiros de uma conversa, Blair aponta que, a esse respeito, "a argumentação publicada, tal como encontrada em revistas, artigos em periódicos acadêmicos ou livros, está mais relacionada aos discursos retóricos monologais do que às conversas". Se "discursos retóricos monologais" fossem usados como um termo que inclui tais artefatos escritos, isso seria uma melhoria do ponto de vista retórico. Mas, nesse caso, por que não usar termos mais precisos, que expressem a diferença entre argumentação retórica e dialética como uma comunicação unilateral ou bidirecional? Talvez essa opção não seja atraente porque estraga a simetria na conexão de Blair sobre a dialética com as discussões na comunicação oral face a face com um argumentador por vez. Por outro lado, outros podem se opor a isso e sustentar a visão, como eu, de que as abordagens dialéticas não se restringem a situações orais. Os pragmadialéticos, por exemplo, aplicam sua teoria da argumentação a muitos outros tipos de textos além das discussões orais com um falando de cada vez. Um exemplo é a análise de van Eemeren e Houtlosser (2002) do jornal publicitário mundial da Shell em defesa dos envolvimentos da empresa na Nigéria (ver Leff, 2006), texto que certamente se encaixa melhor na situação retórica do que na situação comunicativa dialética descrita por Blair.

Meu relato da visão de Blair também pode ser excessivamente crítico por outro motivo. Na conclusão, ele usa a expressão "na argumentação a retórica e a dialética refletem diferentes contextos paradigmáticos" e fala sobre "contextos tipicamente retóricos e tipicamente dialéticos" (BLAIR, 2012, p. 162, grifo nosso). Esses modificadores obviamente diminuem a distância entre a visão de Blair e a minha e 
podem ser entendidos como uma abertura para as objeções que levantei. Nesse caso, a questão ainda depende do sentido em que usamos a palavra 'paradigma'. Isso significa que discursos retóricos monologais versus conversações seja um paradigma no sentido histórico, isto é, que os campos da teoria da argumentação se desenvolveram e alcançaram suas respectivas propriedades como resultado dos dois contextos práticos típicos? Ou será que "paradigmático" se refere a contextos quintessenciais ou arquetípicos em um sentido contemporâneo ou a-histórico? No primeiro caso, a distinção de Blair é apropriada como uma caracterização geral dos dois campos. Nesse sentido, a tricotomia corresponde muito bem à visão de Johnson - e à minha - de que os membros de cada comunidade de estudo "estão ligados por uma história, uma tradição e uma educação comuns, além de um interesse contínuo em uma ampla gama de questões e problemas" (JOHNSON, 2020 [2009], p. 270)

No entanto, conforme li no artigo de Blair, a tricotomia é sugerida principalmente como um delineamento relevante da relação contemporânea entre os campos. E, nesse segundo caso, em que "paradigma" se refere ao tipo quintessencial de texto estudado, a distinção entre os discursos retóricos monologais e a conversação estreita os domínios dos respectivos campos de maneira em que pelo menos os retóricos, independentemente da orientação, não podem se identificar.

Tenho mais algumas reservas específicas sobre o que constitui a típica situação retórica do discurso retórico monologal. De acordo com Blair (2012, p. 161), os discursos retóricos monologais são monólogos dirigidos a uma audiência de massa geralmente heterogênea. Como apontado em seu artigo "The limits of the dialogue model of argument", os discursos são dialógicos apenas no sentido metafórico (BLAIR, 1998, p. 337), embora sejam (explícita ou implicitamente) dialéticos, ou seja, se relacionem a contra-argumentos. Acho essa distinção apropriada e esclarecedora, mas não creio que o contraste de Blair no presente artigo dê a atenção devida à complexidade da situação do discurso retórico e ao papel do público. É claro que os discursos retóricos são formalmente monológicas, na medida em que o retor tem a palavra; e a audiência é 'não interativa' na medida em que os membros da audiência assistem ao discurso como ouvintes e não interagem como argumentadores. Mas, em outro sentido, muitas situações retóricas não são monológicas; elas são trialógicas (como no termo alemão “trialogisch”, ver Dieckmann, 1981, p. 218; Klein, 1991, p. 355-356). Eles ocorrem em ambientes que envolvem três partes em interação: dois argumentadores e uma audiência que toma decisões - "mediadores de mudança” na acepção de Bitzer (1968). A audiência desempenha um papel vital na interação em uma capacidade que a torna constitutiva da situação argumentativa. Assim, o contexto paradigmático da retórica 
deliberativa "pura" é uma situação de debate tripartido. Em contraste, a situação dialética "pura" é dialógica, conforme definida por Blair e também em relação à constelação de participantes. Apenas os dois debatedores constituem esse tipo de discurso, assistidos ou não por uma audiência. A questão é que um público dialético presente atua como espectador, não como constituintes no cenário argumentativo, ou seja, a audiência não faz diferença para o desenvolvimento da discussão crítica, o desempenho dos argumentadores ou o resultado da interação (JØRGENSEN, 1995; 1998, p. 438-439; Kock, 2007, p. 109). Observe que a palavra "puro" é inserida acima para deixar espaço para as muitas situações sobrepostas e misturadas entre os dois paradigmas que ambos - Krabbe (2000) e o próprio Blair (1998) - esclareceram de maneira que são consistentes com minha própria abordagem ao problema aqui.

Uma segunda reserva diz respeito à composição e ao tamanho do auditório retórico. De comum acordo, os discursos retóricos monologais públicos são tipicamente dirigidos a grandes conjuntos de pessoas, constituídos por segmentos mais ou menos diversos, e a noção homogênea é sempre relativa quando se trata de auditórios compostos por vários ou muitos membros. Mas os discursos retóricos também podem ser dirigidos a um grupo bastante homogêneo de indivíduos, por exemplo, especialistas em um determinado campo ou grupo político, e isso não os torna menos típicos do discurso retórico. O auditório retórico não precisa, também, ser um auditório de massa. $O$ auditório é muitas vezes um pequeno grupo, às vezes apenas uma única pessoa ou mesmo o próprio retor, caso em que temos "autodeliberação" (PERELMAN; OLBRECHTS-TYTECA, 1969, § 8-9).

Tendo discutido retórica versus dialética, Blair lidou bastante resumidamente com a lógica. Pela definição de que "lógica” "é mais amplamente entendida no âmbito (estudo) das normas do bom raciocínio", ele sugere que "a lógica dos argumentos consistirá nas normas apropriadas do raciocínio exibidas em, ou convidadas por, argumentos usados na argumentação", seja em discursos ou conversação. Além disso, ele aponta que cada um dos três campos tem "um ramo descritivo e um ramo normativo" (BLAIR, 2012, p. 161-162). Portanto, reconheço que Blair não sugere que a lógica é necessária para fornecer à dialética e à retórica normas para uma boa argumentação/argumentos/argumentação em termos gerais, mas apenas com as normas que dizem respeito ao raciocínio. Isso abre a questão de como a "razão" é definida. Refere-se mais estritamente à "racionalidade" e aos critérios associados à lógica formal tradicional e à lógica informal inferencial, por exemplo, validade dedutiva, solidez, força indutiva etc.? Percebi que é assim que devemos entender a tricotomia de Blair. Em sua conclusão, entretanto, ele usa a expressão com conotações mais amplas: 
a lógica é o estudo das "normas de razoabilidade dos argumentos" (p. 162). Se a razoabilidade se refere a uma noção ampliada de racionalidade como comentada por Perelman (1984), Perelman e Olbrecths-Tyteca (1969) ou Toulmin (1958, 1981, 2001), a remissão dessas normas à lógica torna-se problemática. Na minha visão retórica, não se pode separar razoabilidade de boa argumentação, mas "razoável" significa "legítimo" ou "aceitável" em vez de "correto" de acordo com certos padrões lógicos universais, não importa como eles sejam definidos (cf. Tindale, 1999). A legitimidade e a aceitabilidade abrangem, entre outras coisas, a conduta argumentativa ética e as considerações relativas à substância dos argumentos, incluindo o mérito das opiniões e valores apelados. Tais normas - por exemplo, o "padrão de justiça”, em Jørgensen (2007) - não podem ser o que Blair tem em mente para a lógica, uma vez que isso significaria que, para ser um lógico, deve-se primeiro ser retórico e dialético.

\section{A distinção de Kock}

Mudemos agora o foco da atenção para a distinção entre os campos que Blair (2012) discute como uma alternativa ao modelo padrão de Wenzel, referindo-se especificamente ao artigo de Christian Kock (2009) "Choice is not True or False: The Domain of Rhetorical Argumentation". Kock (2009) torna "o tipo de argumento" - o "assunto" ou "o domínio tópico" - o traço distintivo que caracteriza a argumentação retórica, ou seja, o tipo de questão discutida. De fato, Kock (2007; 2009) não faz uma distinção tripartida entre os campos, mas, em vez disso, ele propõe uma distinção entre, de um lado, a argumentação prática projetada para questões de ação e, de outro lado, a argumentação projetada para estabelecer questões de fato. A argumentação retórica está "centralmente preocupada com a escolha da ação" (KOCK, 2009, p. 65). A argumentação dirigida à ação envolve valores, e as afirmações sobre ação e valores não são verdadeiras ou falsas. A distinção, portanto, repousa em uma dicotomia entre questões que têm valor de verdade e questões que não têm. Enquanto o domínio da retórica é a escolha da ação, o domínio da lógica e da dialética presumivelmente está centrado em questões de fato.

Blair (2012, p. 156) levanta duas objeções à visão de Kock, das quais considerarei apenas a primeira, a saber, a implicação de que a retórica não deve estar comprometida com a verdade. Por um lado, dificilmente se pode afirmar que Kock leva sua visão a tal extremo. Ele explicitamente leva em consideração o fato óbvio de que a principal proposta de ação de um retor "pode ser apoiada por proposições que podem ser 
verdadeiras (ou prováveis)" (KOCK, 2009, p. 76). Nesse nível do contexto argumentativo, a retórica certamente está comprometida com a verdade e seria absurdo se Kock estivesse negando isso. Por outro lado, a objeção é relevante em relação à implicação de que a argumentação retórica deve ser limitada ao domínio que tem uma proposta de escolha como sua principal reivindicação (implícita ou explícita) na situação específica. Embora Kock em nenhum lugar afirme explicitamente que a argumentação retórica é exclusivamente restrita à escolha e "ações originadas internamente à pessoa" (2009, p. 62), sua insistência na importância dominante da dicotomia convida fortemente o leitor a tirar essa conclusão. Mas uma equação entre o discurso argumentativo retórico e o domínio de escolha é uma simplificação excessiva e, portanto, a distinção escolha de ação - verdade dos fatos é muito estreita, traçando uma linha mais nítida entre os campos do que é apropriado segundo meu ponto de vista. A este respeito, os modelos alternativos de Kock e Blair são idênticos.

Em conexão com sua equação proposta, parece estranho que Kock defenda uma concepção estreita de argumentação retórica comparada com a visão ampla de retórica que ele representa. A discrepância é evidenciada por suas observações introdutórias sobre o amplo escopo da retórica (2009, p. 62). Ele declara sua visão ampla, citando a famosa definição de George Campbell a fim de enfatizar que os fins do discurso retórico são múltiplos e que a argumentação é apenas parte da retórica. Por exemplo, diz ele, o objetivo de agradar a imaginação "não pertenceria ao objeto da teoria da argumentação". No entanto, outro dos quatro objetivos, que é o de esclarecer o entendimento, muitas vezes requer argumentação, também em situações comunicativas que se enquadram no campo discursivo da retórica. Por exemplo, um retor pode tentar explicar a um novato como um dispositivo técnico funciona ou explicá-lo a alguém que acredita que ele funciona de uma maneira diferente. Nesses casos, o problema não é uma escolha; a principal alegação do retor é uma questão de fato - verdadeiro ou falso - e ele produzirá argumentos, seja por raciocínio demonstrativo ou por convencimento/persuasão na tentativa de superar a divergência de crença.

O contraexemplo serve apenas para refutar a afirmação de que a argumentação retórica está confinada a questões de ação. Seu propósito não é contradizer o fato de que a retórica deliberativa é tipicamente argumentação relacionada à ação baseada em valores, ou que este tipo de argumentação tem sido o paradigma dominante para a teoria da argumentação retórica ao longo da história - e ainda é para a retórica deliberativa em particular. Além disso, conforme leio Kock, seu principal objetivo não é fazer uma divisão que separe a retórica dos outros campos da tríade. É, antes, para 
promover o entendimento de que argumentamos diferentemente nos dois domínios, e que, portanto, o crítico não pode aplicar uma única e mesma descrição teórica a ambos, ou avaliar a argumentação pertencente a esses dois domínios pelas mesmas normas e padrões. Se essa interpretação for válida, concordo totalmente com o ponto de vista de Kock. E isso me leva à última seção sobre as implicações relativas à relação entre os campos na tríade e à razão pela qual sugiro que paremos de reduzir suas diferenças a uma só característica.

\section{Implicações}

Argumentei que, ao buscar a diferença essencial, estamos fadados a acabar apresentando a conexão de maneiras com as quais os integrantes dos campos não podem se identificar - maneiras que encobrem suas propriedades de mesclagem e que contradizem o pluralismo de cada campo e a possibilidade de pontes teóricas particulares entre os campos.

É um topos acadêmico que o progresso na pesquisa, às vezes, seja alcançado por um passo atrás em vez de à frente. É outro topos que o trabalho acadêmico, por natureza, envolva redução em algum grau. A questão ocorre quando nossas reduções trazem uma visão fecunda e ordem para as complexidades da realidade e quando elas transgridem essa linha simplificando demais essas complexidades. Como Gilbert expressa, devemos tratar as distinções pelo que elas são - "não uma descrição da realidade, mas sim um auxílio para entender a Teoria da Argumentação" -, não as transformando em separações (GILBERT, 2014, p. 2). Ambos os topoi são relevantes para minha posição a respeito da relação entre os campos da tríade.

Sugiro que voltemos a listar as várias diferenças e semelhanças tradicionais típicas entre a retórica, a dialética e a lógica, e paremos de procurar a diferença essencial. Em minha opinião, essas listas têm um propósito pedagógico. As listas são do tipo que, por exemplo, Leff (2000) apresenta, cobrindo itens como assunto, propósito, escopo, esfera, legitimidade dos apelos intelectuais e emocionais, formatos de interação comunicativa, estilo etc. O gráfico de McAdon, retrata os três campos no contexto do pensamento de Aristóteles e é outro exemplo, comparando-os com relação aos participantes, público, domínio/prática, propósito, metodologia, pontos de partida, ferramentas de raciocínio (McADON, p. 150). De acordo com a visão de Johnson, eles também nos ajudam a entender de onde nós, pertencentes a um dos 
campos, viemos, o que construímos e temos em comum e como nossos campos se relacionam entre si em uma perspectiva mais ampla.

Agora, todas as propriedades dos campos em tais listas são mais ou menos típicas e em cada campo encontramos exceções. Desde que apresentemos um conjunto de pontos de comparação típicos, é provável que não prejudiquem a compreensão das complexidades da tríade. Mas quanto mais reduzimos seu número, em particular se exaltarmos um deles à característica essencial, mais corremos o risco de simplificações grosseiras e deturpações do estado de nossa arte.

Nas palavras de Leff, corremos, portanto, o risco de "pureza compartimentada" (LEFF, 2006, p. 199), em contraste com a maneira como a teoria da argumentação moderna de fato se desenvolveu. Como Leff aponta a este respeito, tem havido uma tendência geral de integração dentro do campo da teoria da argumentação. A nova retórica de Perelman integra retórica com dialética nesta ordem hierárquica; a pragmadialética em sua fase posterior também o faz, mas inclui a retórica sob o domínio da dialética, utilizando o termo "manobra estratégica"; a teoria do manifesto da racionalidade, de Johnson (2000) combina a lógica informal com uma abordagem dialética, e assim por diante.

Permitam-me, para concluir, indicar o tipo de pluralismo que defendo e minha visão da integração das teorias da argumentação. Nenhum dos três campos é capaz de capturar sozinho a diversidade do discurso argumentativo. Eles se complementam, e qualquer campo ou combinações teóricas que utilizemos dependem de nossa formação individual dentro (ou fora) da tríade, nossa orientação teórica, o tipo de discurso ou o artefato argumentativo que estudamos, o aspecto ou a questão de pesquisa que investigamos etc. A onipresença e a diversidade do ato argumentativo na comunicação humana tornam o campo da argumentação muito multifacetado para ser coberto por um dos campos (ou pela tríade como um todo). É necessário todo o tipo de coisa para fazer o mundo, como diz o ditado, o que não nos isenta da escolha individual da "coisa" apropriada que atende ao propósito em cada caso. O reconhecimento do pluralismo da teoria da argumentação, é claro, não significa que qualquer coisa vale para o crítico. Embora eu endosse o pluralismo teórico e o tipo indicado de visões integradoras, eu, no entanto, me oponho ao tipo de integração que busca teorias argumentativas universais (JØRGENSEN, 2009). Assim, devido à natureza multifacetada do discurso argumentativo, concordo com a visão fundamental de Kock, ou seja, que não podemos abordar os dois domínios que ele delineia pelo mesmo aparato descritivo e normas avaliativas. E para terminar com outro exemplo, concordo plenamente com o ponto de vista de Blair (1998), quando ele desafia as teorias que 
têm o diálogo como paradigma descritivo e normativo: existe uma diferença entre descritivo e normativo tanto em discursos retóricos monologais contínuos como em conversas em que os expositores se revezam.

Agradecimentos: Agradeço ao Professor Michael Gilbert e ao revisor anônimo por seus comentários construtivos sobre o artigo da conferência e o manuscrito revisado.

\section{REFERÊNCIAS}

BITZER, Lloyd F. The Rhetorical Situation. Philosophy and Rhetoric, v. 1, n. 1, p. 1-14, 1968

BLAIR, J. Anthony. The Limits of the Dialogue Model of Argument. Argumentation, n. 12, p. 325-339, 1998.

BLAIR, J. Anthony. Rhetoric, Dialectic, and Logic as Related to Argument. Philosophy and Rhetoric, n. 45, p. 148-164, 2012.

DIECKMANN, Walther. Politische Sprache, politische Kommunikation. Heidelberg: Carl Winter Universitätsverlag, 1981.

EEMEREN, Frans H. van; HOUTLOSSER, Peter. Strategic Maneuvering: Maintaining a Delicate Balance. In: EEMEREN, Frans H. van; HOUTLOSSER, Peter (eds.). Dialectic and Rhetoric: The Warp and Woof of Argument Analysis. Dordrecht: Kluwer Academic Publishers, 2002. p. 131159 .

FRENTZ, Thomas S. Rhetorical Conversation, Time, and Moral Action. In: LUCAITES, John Louis; CONDIT, Celeste Michele; CAUDILL, Sally (eds.). Contemporary Rhetorical Theory: A Reader. New York: The Guilford Press, 1999 [1985]. p. 288-305.

GILBERT Michael A. Commentary on: Charlotte Jørgensen's "Rhetoric, Dialectic, and Logic: The Triad Decompartmentalized". In: INTERNATIONAL CONFERENCE OF THE ONTARIO SOCIETY FOR THE STUDY OF ARGUMENTATION (OSSA), 10, 2013, Windsor, Proceedings [... ]. Windsor: OSSA, 2014. p. 1-4 (CD-ROM).

HAUSER, Gerald A. Introduction to Rhetorical Theory. 2.ed. Prospect Heights: Waveland Press, 2002.

JOHNSON, Ralph H. Manifest Rationality: A Pragmatic Theory of Argument. Mahwah: Lawrence Erlbaum Associates, 2000.

JOHNSON, Ralph H. Revisiting the Logical/dialectical/rhetorical Triumvirate. In: INTERNATIONAL CONFERENCE OF THE ONTARIO SOCIETY FOR THE STUDY OF ARGUMENTATION (OSSA), 09, 2009, Windsor, Proceedings [...]. Windsor: OSSA, 2009. p. 113 (CD-ROM).

JOHNSON, Ralph H. Revisitando o triunvirato lógica/dialética/retórica. Tradução: Eduardo Lopes Piris e Paulo Roberto Gonçalves-Segundo. EID\&A - Revista Eletrônica de Estudos Integrados em Discurso e Argumentação, Ilhéus, n. 20, v. 1, p. 254-273, 2020 [2009]. DOI 10.17648/eidea-20-v1-2708. 
JØRGENSEN, Charlotte. Debattens væsen og uvæsen: Om fjendtlighed i offentlig debat. Retorik Studier, n. 10, p. 3-43, 1995.

JØRGENSEN, Charlotte. Public Debate - An Act of Hostility? Argumentation, n. 12, p. 431-443, 1998.

JøRGENSEN, Charlotte. The Relevance of Intention in Argument Evaluation. Argumentation, n. 21, p. 165-174, 2007.

JØRGENSEN, Charlotte. Argumentation. In: JØRGENSEN, Charlotte; VILLADSEN, Lisa (eds.). Retorik. Teori og praksis. Copenhagen: Samfundslitteratur, 2009. p. 129-158).

JØRGENSEN, Charlotte. Rhetoric, Dialectic and Logic: The Triad Decompartmentalized. In: INTERNATIONAL CONFERENCE OF THE ONTARIO SOCIETY FOR THE STUDY OF ARGUMENTATION (OSSA), 10, 2013, Windsor, Proceedings [... ]. Windsor: OSSA, 2014. p. 1-9 (CD-ROM).

KENNEDY, George A. Aristotle - On Rhetoric: A Theory of Civic Discourse. New York: Oxford University Press, 1991.

KLEIN, Josef. Zur Rhetorik politischer Fernsehdiskussionen. In: UEDING, Gert (ed.). Rhetorik zwischen den Wissenschaften: Geschichte, System, Praxis als Probleme des "Historischen Wörterbuchs der Rhetorik”. Tübingen: Max Niemeyer Verlag, 1991. p. 353-362.

KOCK, Christian. Norms of Legitimate Dissensus. Informal Logic, n. 27, p. 179-196, 2007.

KOCK, Christian. Choice is not True or False: The Domain of Rhetorical Argumentation. Argumentation, n. 23, p. 61-80, 2009.

KRABBE, Erik C. W. Meeting in the House of Callias: Rhetoric and Dialectic. Argumentation, n. 14, p. 205-217, 2000.

LEFF, Michael. Rhetoric and Dialectic in the Twenty-first Century. Argumentation, n. 14, p. 241-254, 2000.

LEFF, Michael. Rhetoric, Dialectic, and the Functions of Argument. In: HOUTLOSSER, Peter et al (eds). Considering Pragma-Dialectics: A festschrift for Frans H. van Eemeren on the occasion of his 6oth birthday. Mahwah: Lawrence Erlbaum Associates, 2006. p. 199-209.

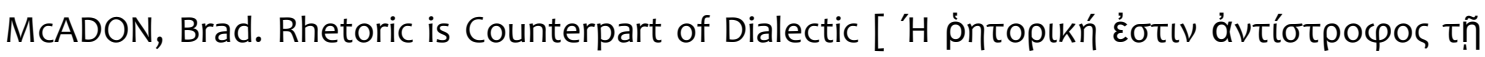
$\delta \iota \alpha \lambda \varepsilon k \tau \iota k n ̃]$. Philosophy and Rhetoric, n. 34, p. 113-150, 2001.

PERELMAN, Chaïm. The New Rhetoric and the Rhetoricians: Remembrances and Comments. Quarterly Journal of Speech, n. 70, p. 188-196, 1984.

PERELMAN, Chaïm; OLBRECHTS-TYTECA, Lucie. The New Rhetoric. A Treatise on Argumentation. Notre Dame: University of Notre Dame Press, 1969.

TINDALE, Christopher W. Acts of Arguing: A Rhetorical Model of Argument. Albany: State University of New York Press, 1999.

TOULMIN, Stephen. The Uses of Argument. Cambridge: Cambridge University Press, 1958.

TOULMIN, Stephen. The Tyranny of Principles. The Hasting Center Report, v. 11, n. 6, p. 31-39, 1981. 
Revista Eletrônica de Estudos Integrados em Discurso e Argumentação, n.21, v.1, abr.2021.

TOULMIN, Stephen. Return to Reason. Cambridge: Harvard University Press, 2001.

WENZEL, Joseph. Three Perspectives on Argument: Rhetoric, Dialectic, Logic. In: TRAPP, Robert; SCHUETZ, Janice (eds.). Perspectives on Argumentation. Essays in Honor of Wayne Brockriede. Prospect Heights: Waveland Press, 1990. p. 9-26. 